\title{
Experimental investigation of high-viscosity oil-water flow in vertical pipes: flow patterns and pressure gradient
}

\author{
Tarek Ganat ${ }^{1} \cdot$ Syahrir Ridha ${ }^{1} \cdot$ Meftah Hairir $^{2} \cdot$ Juhairi Arisa ${ }^{1} \cdot$ Raoof Gholami ${ }^{3}$
}

Received: 12 February 2019 / Accepted: 6 May 2019 / Published online: 11 May 2019

(c) The Author(s) 2019

\begin{abstract}
Flow experiments have been conducted for two-phase flow in a vertical pipe. The experiments were made for highly viscous oil-water in a stainless pipe at $250 \mathrm{psig}$ pressure through the laboratory-scale flow test equipment. The test section used is a vertical transparent tube of $50 \mathrm{~cm}$ length and $40 \mathrm{~mm}$ ID. The test fluid utilized in this experiments is synthetic oil (viscosity $=35 \mathrm{mPas}$, density $=860 \mathrm{~kg} / \mathrm{m}^{3}$ ) and filtered tap water (interfacial tension $31 \mathrm{mN} / \mathrm{m}$ at $20{ }^{\circ} \mathrm{C}$, viscosity $0.95 \mathrm{mPas}$ at $25{ }^{\circ} \mathrm{C}$ ). The measurements of superficial velocities of oil and water were varied between 0.01 to $3 \mathrm{~m} / \mathrm{s}$. According to the experimental observations using audiovisual recordings, a flow pattern map was identified at different condition. Measuring the variations in pressure gradient and flow patterns at different superficial velocities of two-phase flow, six typical flow patterns were categorized and mapped under two groups, oil-dominant region and water-dominant region, and categorized based on the variations of oil and water superficial velocities, and mixture fluid velocity, at different amount of the water holdup in the vertical tubing. The measurements of the total pressure gradient at five different mixture fluid velocities were conducted verses water holdup in vertical tubing. The results show that all the upward flows show an identical flow pattern, where the pressure gradients increase with increasing mixture fluid velocity and water cut with similar trend. The experiments show a clear peak in the pressure gradient as a result of the frictional factor, specifically at the point of flow patterns occurs (i.e., water holdup 30\%). The results concluded that the pressure gradient is significantly influenced by flow patterns and flow rates. Besides, the oil viscosity has a high effect on the pressure gradients; however, it is observed that at similar water and oil superficial velocities, there is a subsequent increase in the pressure gradient due to the increase in oil viscosity.
\end{abstract}

Keywords Flow pattern $\cdot$ Mixture velocity $\cdot$ High viscosity $\cdot$ Pressure gradient $\cdot$ Flow regime

\section{Introduction}

The worldwide heavy oil resources become very significant as future natural energy. To produce viscous oil-water phase economically, we need to develop more accurate approaches to predict heavy viscous phase flow behavior. Most of the researchers studied the flow regime estimations for lower viscous oils. There are many experimental studies of multiphase stream either in vertical, horizontal or inclined

Tarek Ganat

tarekarbi.ganat@utp.edu.my

1 Petroleum Engineering Department, Universiti Teknologi PETRONAS, 32610 Seri Iskandar, Perak, Malaysia

2 Department of Mechanical Engineering, International Islamic University Malaysia, 10, 50728 Kuala Lumpur, Malaysia

3 Petroleum Engineering Department, Curtin University, 1437, 98008 Miri, Sarawak, Malaysia tubing flow, and the studies concentrated on gas-liquid phase flow. Most of the available literature focused generally on gas-liquid phase methods with quite a few studies focused on liquid-liquid flows systems. The data found from the literature review show that there are few vertical flow test data existing for the pressure gradient of highly viscous oil and water flow.

Russell et al. (1959) studied the pressure drop and flow patterns phenomena for two liquids, through a horizontal tube $(2.05 \mathrm{~cm} \mathrm{ID}$, oil viscosity $=0.018$ Pas, specific gravity $=0.834$ at $25^{\circ} \mathrm{C}$ ). They investigated the volume ratios of oil and water from 0.1 to 10 , at varied superficial water velocity between 0.035 to $1.08 \mathrm{~m} / \mathrm{s}$. They correlated their laminar flow theoretical model using varied parallel plates. They observed three different flow patterns consist of stratified, bubble and mixed flows. Their results show that the pressure drop figures matched with their imperial model in the laminar region. Govier et al. (1961) were the very

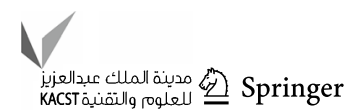


earlier researchers to study two immiscible liquids in vertical flow, with the ID of $26.4 \mathrm{~mm}$ and $11,278 \mathrm{~mm}$ length with several oil physical properties $\left(\rho_{\mathrm{o}}=880-780 \mathrm{~kg} / \mathrm{m}^{3}\right.$, $\left.\eta_{\mathrm{o}}=0.936 \mathrm{mPas}\right)$. Their experiments were mostly focused on visual observations. The authors in the paper identified an effective way of identifying the flow pattern via a mini-electricity probe. Other mechanistic models and experimental work on high-viscosity liquid/gas systems were conducted by some researchers, e.g., Mandhane et al. (1974), Taitel and Dukler (1976), and Petalas and Aziz (1998). Even these mechanistic and experimental models have been broadly customized and certified for lower viscous gas-liquid flows, but their precision for highly viscous liquids is yet to be measured. Likewise, their mechanical simulations to estimate the intermittent dynamical structures and the pressure drop (Barnea and Taitel (1993) and Cook and Behnia (2000)) need to be verified and certified for heavy viscous oil. Vigneaux et al. (1988) performed tests on two immiscible liquids flow via a vertical tube using $200 \mathrm{~mm}$ ID and defined the region of transient flow. This was recognized through the flow at the water holdup volume, $\alpha w$, between 0.2 to 0.3 . But, their results never identified plug or slug flow pattern, in contrast to what Zavareh et al. (1988) had been observed in his experiments. Flores et al. (1999) developed six conductance probes axially located in a 50.8-mm-ID tube to study oil and water flow patterns. They identified that water-dominated flow regime comprised DO/W, VFD O/W and $\mathrm{O} / \mathrm{W}$, while the oil-dominated flows were combined by DW/O, VFD W/O as well as W/O. Farrar and Bruun (1996) studied two-liquid system flow patterns in a vertical tube with inside diameter of $78 \mathrm{~mm}$ and $1500 \mathrm{~mm}$ length. They used an acrylic transparent pipe to observe the flow pattern. Besides, a computer-aided thermoanemometry technique was used to investigate the developing patterns. A numerical system was used to differentiate between the dispersed and continuous phase. Their result identified three different flow patterns which are slug, bubble and bubble flow with a spherical dome. Experimental work on oil-water flow pattern was applied by Jana et al. (2006). They detected many flow regimes by applying a parallel line conductivity probe. Oddie et al. (2003) used electrical probes in their experiments to study vertical oil-water phase flow through a 150-mm-ID vertical tube. Zhao et al. (2006) investigated the dispersed oil in water in a 40-mm ID and a length of $3800 \mathrm{~mm}$ vertical tubing, using oil density $\rho_{\mathrm{o}}=824 \mathrm{~kg} / \mathrm{m}^{3}$ and viscosity $\eta_{\mathrm{o}}=4.1 \mathrm{mPas}$. They generated a map in organized system which relates to the superficial velocities of oil and water. Du et al. (2012) used a mini-conductance probe array to classify the flow patterns in a 20-mm ID tube. The authors observed the following flow patterns: VFD O/W, DW/O, D OS/W, DO/W and TF. To categorize oil and water flow pattern in a $125-\mathrm{mm}$ ID vertical tube, a dual-ring conductance probe array was used by Xu et al. (2016). Slippage effect was experimentally investigated by Mydlarz-Gabryk et al. (2014) in two-phase flow via 30-mm-ID vertical tubing. They concluded that the slip ratio was reliant on flow pattern changes.

The ability to measure the water holdup of an oil-water phase flow was studied by Jian et al. (2012) on the vertical tubing. They measured both frictional pressure drops and gravity. Their tests were performed on the mixture fluid velocities of the oil and water at a range of $0.28-4.65 \mathrm{~m} / \mathrm{s}$ with varied oil volume fraction from 0 to 1.0. They show that the determined oil holdups are reasonable with an error of $\pm 10 \%$. Roriguez and Oliemans (2006) used two-liquid phase to carry out the experiments on horizontal and a little inclined steel pipe. Inorganic oil and saline water were used in a $15-\mathrm{m}$-long pipe with $8.28 \mathrm{~cm}$ ID. They determined holdups, flow patterns and pressure gradients at different flow rates for tube inclination of $-5^{\circ},-2^{\circ},-1.5^{\circ}, 0^{\circ}, 1^{\circ}, 2^{\circ}$ and $5^{\circ}$. The authors achieved the identification of the flow patterns and their boundaries by studying the variations from the homogeneous performance. They compared the measured pressure gradient and holdup data with the obtained data using a fluid and homogeneous model. The evaluation of the fluid model showed accuracy for pressure gradient and water holdups $25 \%$ and $15 \%$, respectively. Experimental work for highly viscous oil-water flows with low velocities in horizontal tubing was conducted by McKibben et al. (2002). They noticed that the oil is always present at the wall and water flowing as large slugs once the mixture flows over the steel tubing. They conclude that the pressure gradient decreases not because of water at the tubing wall but because it is accompanied by water slugs with envelope oil. The experiments verified that continuous water aided the flow of viscous oil which can be done in steel tubes. The study proof proposes that the change from the water envelope slug flow regime includes the water holdup and the Froude number.

Zhang and Sarica (2006) presented a combined hydrodynamic model to estimate pressure gradient, flow regime, slug features and liquid holdup, in multiphase flow regime at varied angles between $-90^{\circ}$ to $+90^{\circ}$, whereas the previous model developed by Taitel and Dukler (1976) initiated with the stratified flow. Zhang and Sarica developed a combined model which depends on the existing slug flow. The study showed that the slug flow shares the boundaries of all flow patterns; therefore, it permits the model to estimate the changes from slug flow to any other flow patterns. The proposed model was tested with a wide range of experimental data such as inclination angles, tubing diameter, flow rates, fluid physical properties and flow patterns. Therefore, more work should be carried out to study the performance of the viscous oil flow through the vertical tubing. In this study, flow patterns and pressure gradient measurements will be covered for heavy oil-water phase using synthetic 
oil and filtered water as test fluids. Pressure gradient and flow pattern were acquired at varied oil and water superficial velocities.

\section{Experimental facility and measurement process}

The closed pipe loop of the gas-liquid phase flow facility consisting of the test section, alarming, heating glycol, meters, tanks, separator, pressure transducers and assisting processes was added to adjust the temperatures. The tools were used to study vertical viscous two-phase flow performances at a pressure of $250 \mathrm{psig}$.

\section{Oil and water process}

The experiments were conducted on the multiphase experimental facility shown in the schematic diagram in Fig. 1. The tools and the apparatuses used for the experiments were built to simulate the real flow condition in upward tubing. The fluids used are synthetic oil and filtered water. The rheometer was used to control the oil viscosity. The heavy oil-water physical properties are shown in Table 1. Both liquids are pumped from their tanks throughout the meters and combined together at the T-junction before the test section. Oil process includes the oil tank, oil pump, viscometer, metering device and heat trimmer. The oil tank volume is approximately $25 \mathrm{bbl}$. Heat trimmer is a heater used as a controller to heat oil and regulate the designed liquid temperature within $0.5^{\circ} \mathrm{F}$. Install tube viscometer section together with temperature transmitters at both ends. Also, install a differential pressure transducer to measure the pressure drop. Automatic control valves were utilized to control the oil and water flow rates by positioning them

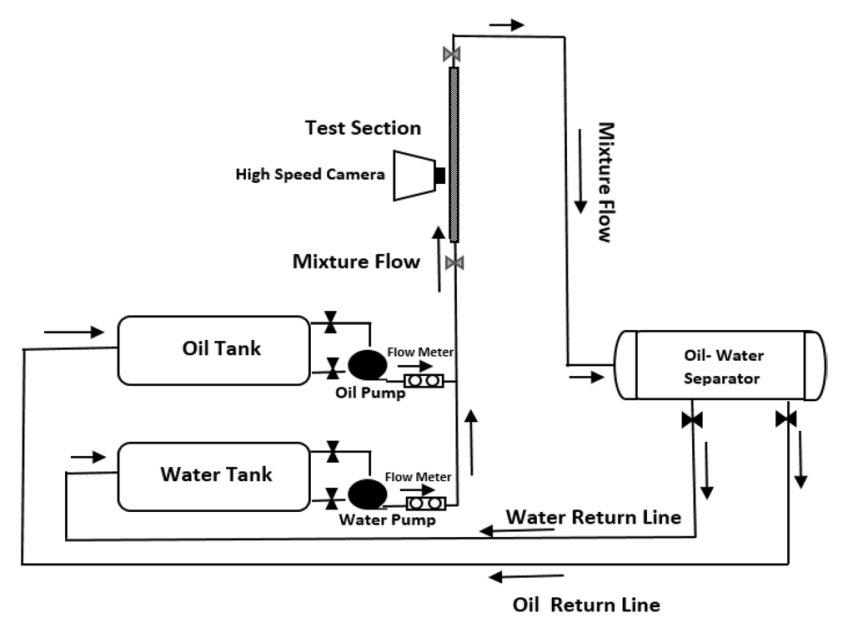

Fig. 1 Diagram of oil-water flow loop
Table 1 Oil-water physical properties

\begin{tabular}{lll}
\hline Property & Water & Oil \\
\hline Density @ $25{ }^{\circ} \mathrm{C}\left(\mathrm{kg} / \mathrm{m}^{3}\right)$ & 998 & 860 \\
Viscosity @ $25^{\circ} \mathrm{C}(\mathrm{mPas})$ & 0.95 & 35 \\
Interfacial tension @ $20^{\circ} \mathrm{C}(\mathrm{mN} / \mathrm{m})$ & Water/oil & 31 \\
\hline
\end{tabular}

downstream of the meters. The water tank volume is approximately $25 \mathrm{bbl}$. Water process contains a water pump, water tank, tube viscometer and metering device. The oil-water separator was utilized to separate the liquids.

The pumps were controlled by speed inverter. Flow rates might be individually varied using the bypass valve and the speed inverter. Figure 2 shows a schematic diagram for the 6-m-long vertical stainless steel pipe section comprises of transparent acrylic test section pipe of $50 \mathrm{~cm}$ length and $40 \mathrm{~mm}$ ID. Stainless steel pipe is connected by a $U$-turn pipe. The test section pipe is positioned at the end of the $6 \mathrm{~m}$ section, where the mixture fluids flowed through the test section that can be seen. Once the flow passes the test section, the mixture flows to the separator and then returned back to storage tanks.

The input oil and water velocities were varied from 0.01 to $3 \mathrm{~m} / \mathrm{s}$ and from 0.01 to $3 \mathrm{~m} / \mathrm{s}$, respectively. The total pressure gradient measurements were taken from the pressure transducers. Most of the experiments were repeated at least two times. The average phase fraction was acquired by the fast-closing valve technique. It comprises of two fast-closing valves installed on pipe. The fast-shutting valves linked by automatic connections were connected in the test section. The fast-shutting valves were then shut to acquire a typical

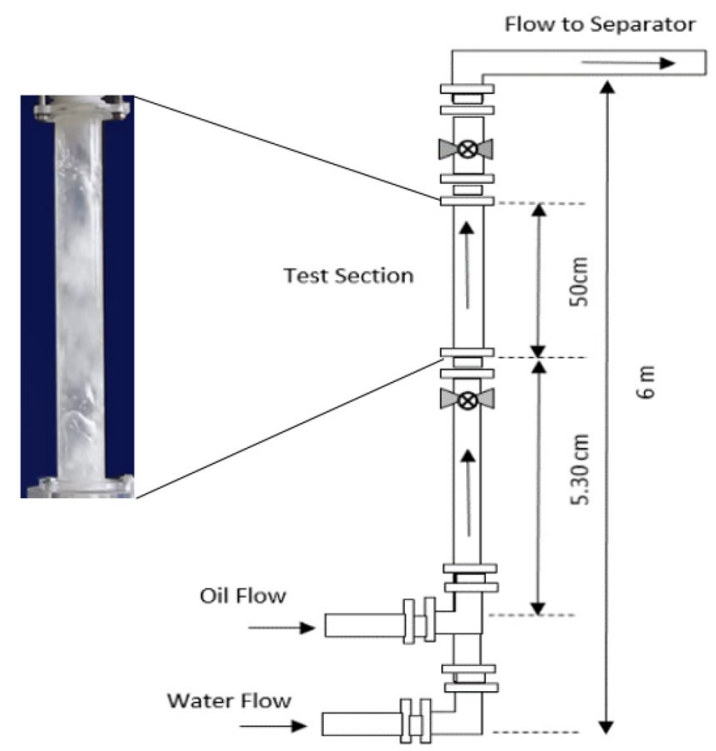

Fig. 2 Diagram of test section 
sample of two-phase flows for volume fraction measurement. The flow pattern was recognized by detecting the flow performance using a high-speed video camera. During the experiment, adequate time was taken to let fully settled flow to be steady. In this work, 102 experiments were conducted for viscous oil-water in vertical tubing.

\section{Measurement principle}

For developed two-phase flow in upward flow pipe, the total pressure gradient is defined as in Eq. 1, as function of frictional, gravity and acceleration pressure drops:

$\mathrm{d} p / \mathrm{d} z=(\mathrm{d} p / \mathrm{d} z)_{f}+(\mathrm{d} p / \mathrm{d} z)_{g}+(\mathrm{d} p / \mathrm{d} z)_{a}$

By neglecting the accelerated pressure drop,

$\mathrm{d} p / \mathrm{d} z=(\mathrm{d} p / \mathrm{d} z)_{f}+(\mathrm{d} p / \mathrm{d} z)_{g}$

where

$(\mathrm{d} p / \mathrm{d} z)_{g}=\rho_{m} g h$

The gravity pressure drop for each phase flow is expressed as follows:

$(\mathrm{d} p / \mathrm{d} z)_{g o}=\rho_{o} g h$

$(\mathrm{d} p / \mathrm{d} z)_{g w}=\rho_{w} g h$

And for frictional pressure drops, Darcy-Weisbach equation is given by:

$(\mathrm{d} p / \mathrm{d} z)_{f}=f_{m} \rho_{m} U^{2} / 2 D$

For turbulent flows (smooth wall pipe), Blasius empirical correlation can be used. The friction loss factor, $f$, is determined from:

$f=0.316(\operatorname{Re})^{-0.25}$

For laminar flows (smooth wall pipe), Poiseuille's law can be used:

$f=64 / R_{\mathrm{e}}$

where $\mathrm{d} p / \mathrm{d} z$ is the pressure gradient, $(\mathrm{Pa} / \mathrm{m}), g$ is the acceleration of gravity, $\left(\mathrm{m} / \mathrm{s}^{2}\right), h$ is the distance of two points, (m), $\rho_{o}$ is the oil density, $\left(\mathrm{kg} / \mathrm{m}^{3}\right), \rho_{w}$ is the water density $(\mathrm{kg} /$ $\left.\mathrm{m}^{3}\right), \rho_{m}$ is the mixture density $\left(\mathrm{kg} / \mathrm{m}^{3}\right)$ and $R_{\mathrm{e}}$ is the Reynolds number.

\section{Experimental results}

As presented in Figs. 3 and 4, there are six flow types of patterns which were identified and mapped under two groups; three flow patterns are classified as oil-dominated flow, and other three patterns are classified as water-dominated flow. The solid line is the margin between oil-dominated and
Water Dominant

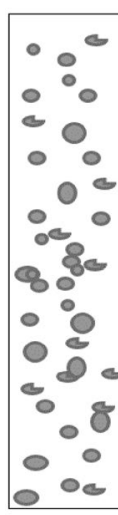

DO/W

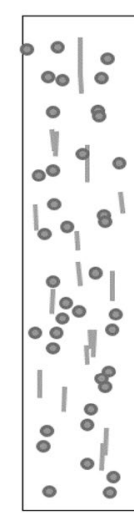

WFD O/W

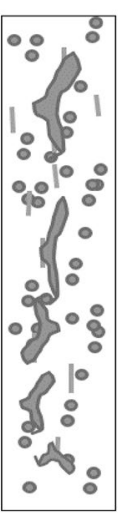

O/W F
Oil Dominant

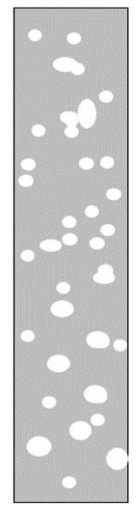

DW/O

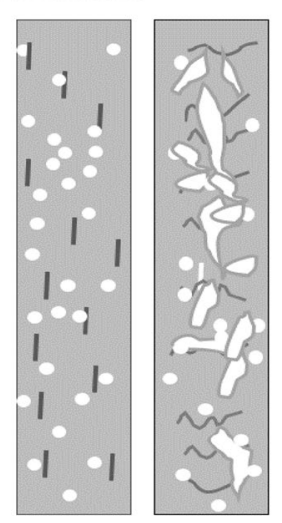

VFD W/O W/O F
Fig. 3 Flow patterns observed in vertical pipe

water-dominated flow patterns. The results show that the area of the oil-dominated flow is smaller than the waterdominated flow area.

\section{Identified flow patterns}

Several flow patterns were noticed at the vertical flow experimental conditions. Two-phase flow regions were identified, oil-dominant region and water-dominant region. This can be visualized with the video recordings. The experimental observations for the flow patterns in the vertical tubing for heavy viscous oil-water flow of $35 \mathrm{mPa}$ are shown in Fig. 3. In Fig. 4, the solid line is the margin of the test data between oil- and water-dominant regions. As being displayed in Fig. 4, the area of the water-dominated flow is bigger than that of the oil-dominated flow. Through the tests, it is observed that by making the superficial water velocity constant and rising the dispersed oil phase velocity, the flow map can alter from DO/W flow to the complex map flow and then to DW/O flow (Fig. 5).

\section{Water-dominant region}

The water-dominant region contains three different flow patterns, O/W F, VFD O/W and DO/W flow. The experiment shows that the DO/W flow is noticed at small superficial water velocity $\left(U_{\mathrm{sw}}<0.8 \mathrm{~m} / \mathrm{s}\right)$ with slightly lower superficial oil velocity $\left(U_{\mathrm{so}}<0.5 \mathrm{~m} / \mathrm{s}\right)$, whereas the input water cut ranges from 22 to $95 \%$. In DO/W flow, big oil droplets in the water phase make some slip rise at DO/W flow with a little rising of superficial oil velocity. This will make the big oil droplets in water to become too small and more often distributed, making VFD O/W flow. In this flow, the water cut is more than $45 \%$. O/W F flow is another water-dominated 
Fig. 4 Flow pattern map at matrix velocity
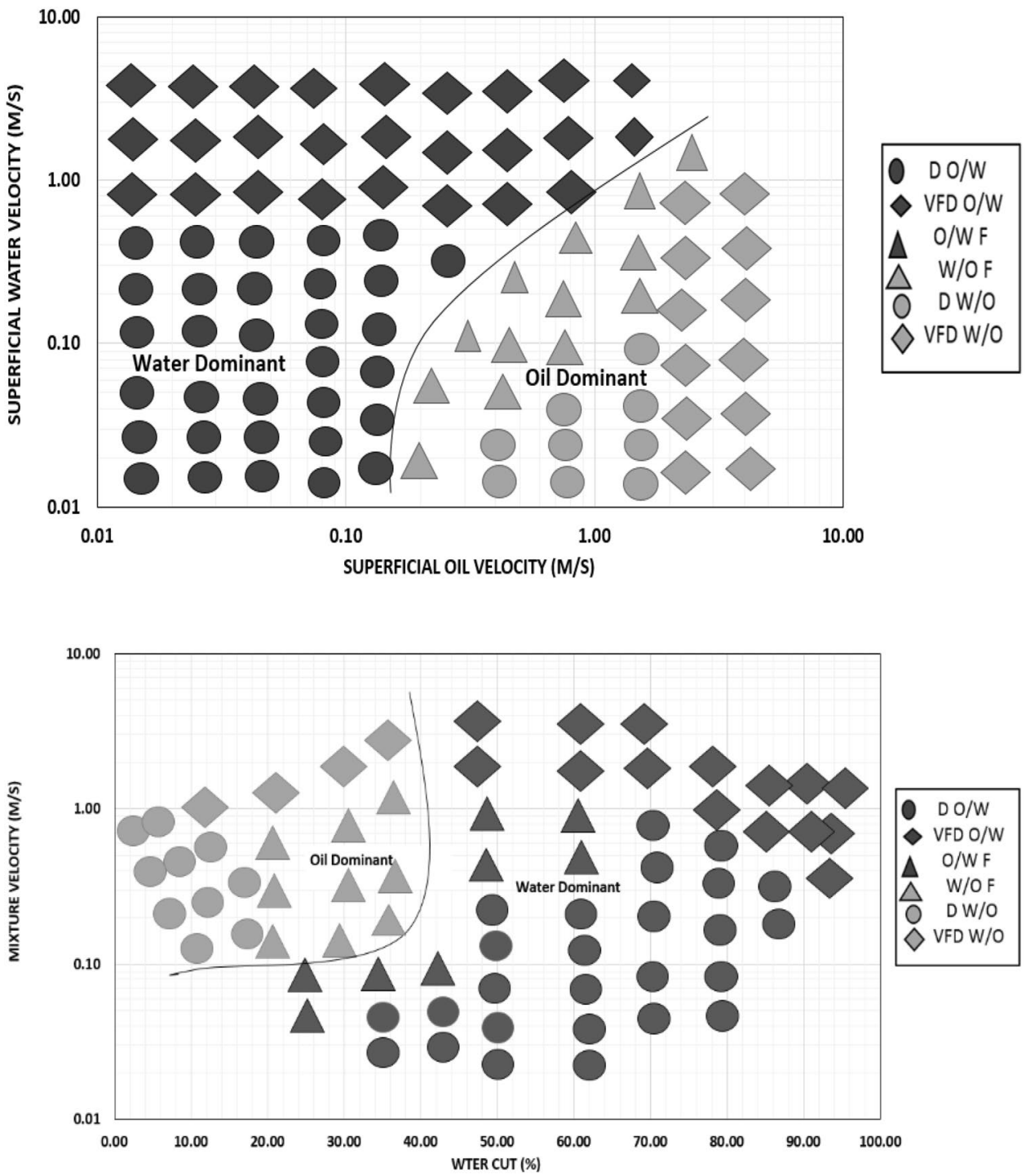

Fig. 5 Flow pattern map as a function of superficial velocities flow seen at the intermediate area to the oil-dominated area with water cut which is below $75 \%$.

\section{Oil-dominant region}

This area includes the following three new patterns: W/O F, VFD W/O and DW/O flow. The area of the oil dominated is of mixture fluid velocity, $U_{\mathrm{m}}$, more than $0.1 \mathrm{~m} / \mathrm{s}$ and water cut is below $45 \%$. The DW/O flow is observed at lower superficial water velocity $\left(U_{\mathrm{sw}}<0.1 \mathrm{~m} / \mathrm{s}\right)$ with slightly higher superficial oil velocity $\left(U_{\mathrm{so}}<1.0 \mathrm{~m} / \mathrm{s}\right)$ at water cut which is less than $20 \%$. The experiment shows that big water droplets in oil are caused once the superficial water velocity increases at the DW/O flow with $U_{\mathrm{so}}>2 \mathrm{~m} / \mathrm{s}$. The turbulent flow in the oil phase is quite high to overwhelm the mixed tension forces of the water drops, causing VFD W/O flow with input water cut below $35 \%$ at mixture fluid velocity higher than $1.5 \mathrm{~m} / \mathrm{s}$, while the W/O F flow is noticed at the intermediate area of O/W F to DW/O, and VFD W/O flow, within water cut range between $18 \%$ and $40 \%$.

\section{Pressure gradient}

Figure 6 shows the five mixture fluid velocities measured in this study $\left(U_{\mathrm{m}}=0.4 \mathrm{~m} / \mathrm{s}, U_{\mathrm{m}}=0.8 \mathrm{~m} / \mathrm{s}, U_{\mathrm{m}}=1 \mathrm{~m} / \mathrm{s}\right.$, $U_{\mathrm{m}}=2 \mathrm{~m} / \mathrm{s}$, and $U_{\mathrm{m}}=3 \mathrm{~m} / \mathrm{s}$ ), to estimate the total pressure gradient as a function of the water holdup in an upward flow. As all flows displayed a similar flow pattern (same trend), the pressure gradients increase with rising both of mixture fluid velocity and water cut. The results show that for a mixture of fluid velocity under $1 \mathrm{~m} / \mathrm{s}$, the pressure gradient displays a gravity-dominated performance with a linear rise from a pure oil to a pure water pressure gradient. Above this velocity $(1 \mathrm{~m} / \mathrm{s})$, there is an obvious peak in the pressure gradient, because of the frictional factor, mainly at the point of flow patterns occurs (at a water holdup 30\%).

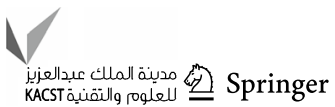


Fig. 6 Vertical flow pattern cross section

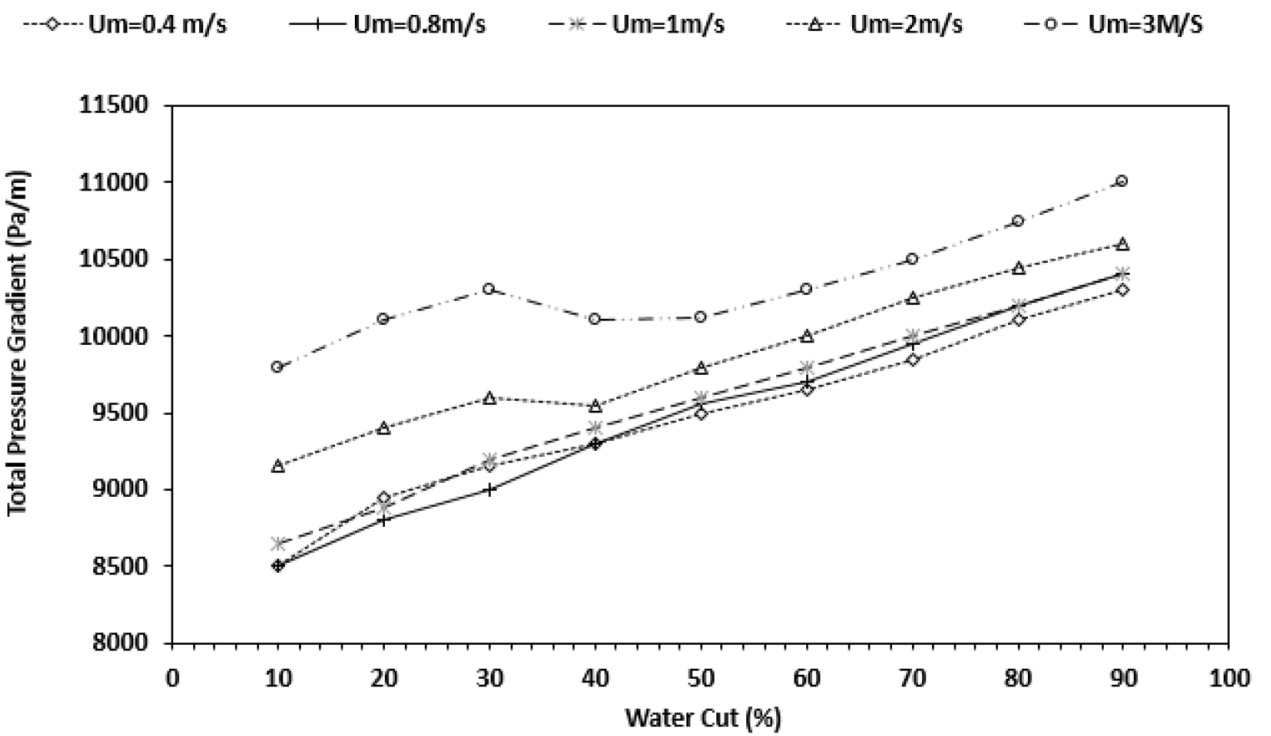

The results show that the large flow rate produces a higher pressure gradient which highly influenced by flow rates and flow patterns. The flow with an oil film on tubing wall tends to make greater pressure gradients. Equivalent to the same oil velocity, shear stress nearby the tubing wall increases once the superficial water velocity increases. This creates a greater pressure gradient. Though high shear stress aids thin oil film at tubing wall and disruption oil into drops. Consequently, water becomes more dominant near the tubing wall. This influences the reducing pressure losses.

Several investigations were performed to study the influence of mixture velocity on the pressure gradient in the vertical pipe at different superficial water velocity for both water continuous phase and oil continuous phase. Figure 7 shows the relationship between the total pressure gradient versus mixture liquid velocity for an oil-water flow system (water is in a continuous phase) at different superficial water velocities. The experiments were performed for $U_{\mathrm{w}}=0.19 \mathrm{~m} / \mathrm{s}, U_{\mathrm{w}}=0.4 \mathrm{~m} / \mathrm{s}$, and $U_{\mathrm{w}}=0.6 \mathrm{~m} / \mathrm{s}$ superficial water velocity. The experiment shows that the total pressure gradient gradually reducing with increasing the velocity of the mixture liquid. This happens at lower superficial water velocity. Conversely, when the oil is in a continuous phase, the total pressure gradient increases once the mixture velocity increased.

Figure 8 presents the influence of superficial water velocities on the total pressure gradients at different superficial oil velocities, $U_{\mathrm{o}},(0.15 \mathrm{~m} / \mathrm{s}, 0.2 \mathrm{~m} / \mathrm{s}, 0.35 \mathrm{~m} / \mathrm{s}$, $0.5 \mathrm{~m} / \mathrm{s}, 0.6 \mathrm{~m} / \mathrm{s}, 0.8 \mathrm{~m} / \mathrm{s}, 1 \mathrm{~m} / \mathrm{s})$. The experiments show that as the superficial water velocity increases the pressure
Fig. 7 Total pressure gradient for oil-water flow system versus mixture liquid velocity at varying superficial water velocity

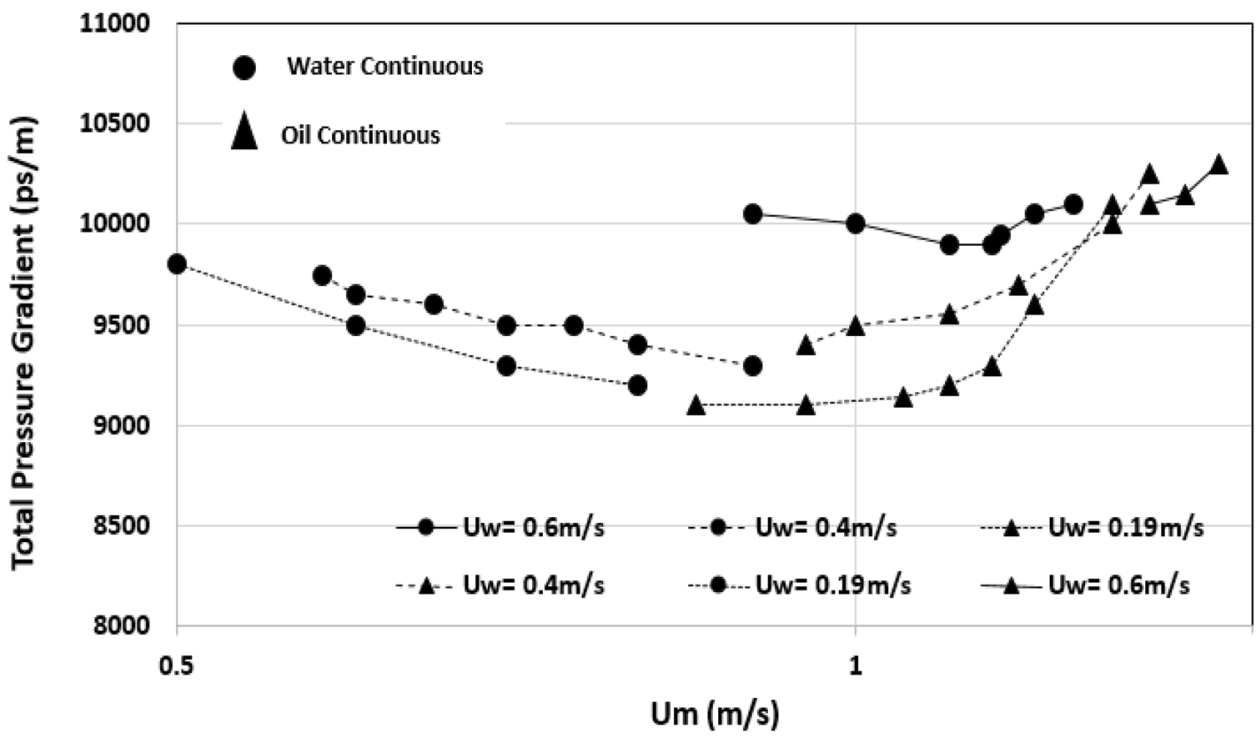


Fig. 8 Total pressure gradient versus superficial water velocity

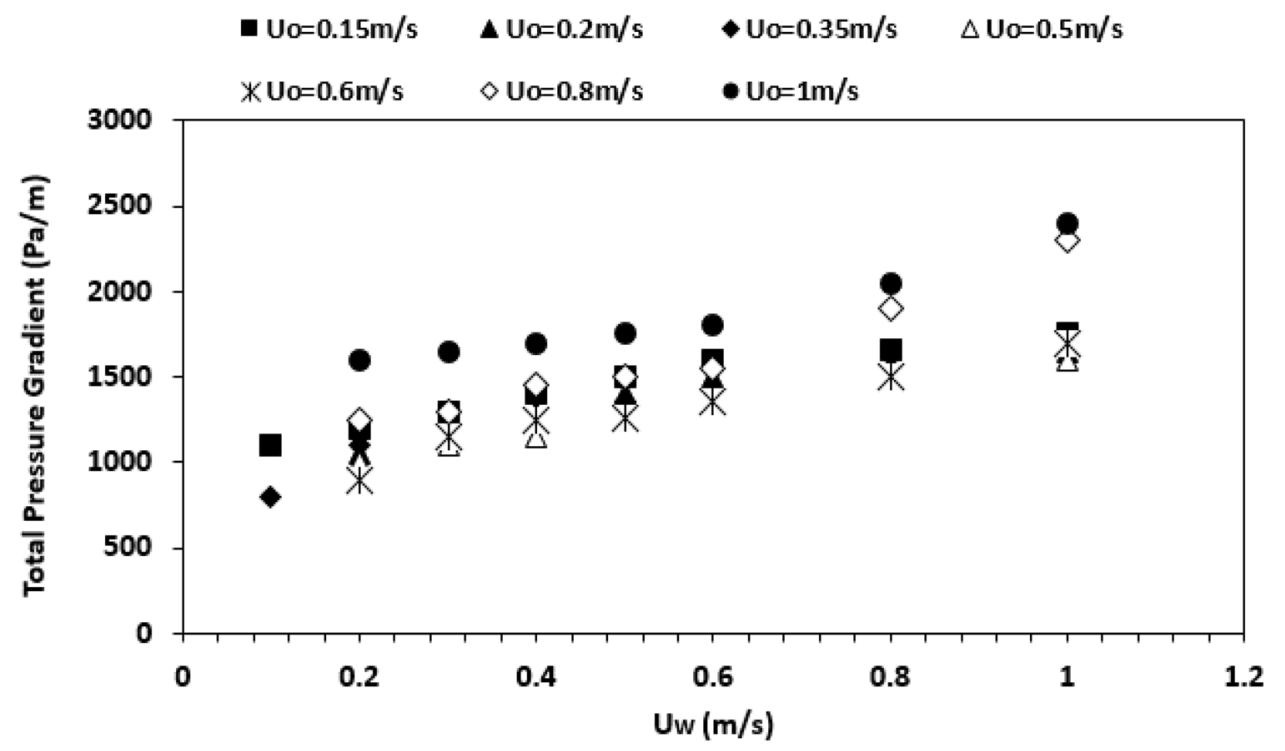

gradients at all the oil velocities increase as well with the same trend.

\section{Frictional pressure gradient}

The effect of input oil/liquid ratio, $R_{\mathrm{o}}$, on the frictional pressure gradient at different superficial water velocity was investigated. Figure 9 shows the results of the oil-water flow system for frictional pressure gradient versus the input oil/ total liquid ratio, $R_{\mathrm{o}}$, with varying water superficial velocity $\left(U_{\mathrm{w}}=0.19 \mathrm{~m} / \mathrm{s}, U_{\mathrm{w}}=0.4 \mathrm{~m} / \mathrm{s}, U_{\mathrm{w}}=0.6 \mathrm{~m} / \mathrm{s}\right)$. The experimental results show that the frictional pressure gradient increases as the $R_{\mathrm{o}}$ increased. Also, the frictional pressure increases once the superficial water velocity increased at the same $R_{\mathrm{o}}$. This can conclude that the frictional pressure gradient is strongly deepened on the mixture velocity.

\section{Conclusions}

To investigate the behavior of the flow pattern and pressure gradient on the viscous oil-water phase flow throughout the vertical tubing, an experimental study was conducted using a laboratory-scale flow test facility. In total, 102 viscous oil-water experiments were conducted for vertical flows. Six flow patterns were observed in this study and clustered into two basic groups as oil-dominated and waterdominated. Water-dominant region includes O/W F, VFD $\mathrm{O} / \mathrm{W}$ and $\mathrm{DO} / \mathrm{W}$ flow. For oil, the dominant includes W/O F, VFD W/O and DW/O flow. Based on the experimental results, a flow pattern map was generated for every condition. Each of the developed maps was clearly identified in both oil-dominant and water-dominant regions, dependent on the variations of superficial velocities of oil and water,
Fig. 9 Frictional pressure gradient for oil-water flow system versus input oil/total liquid ratio

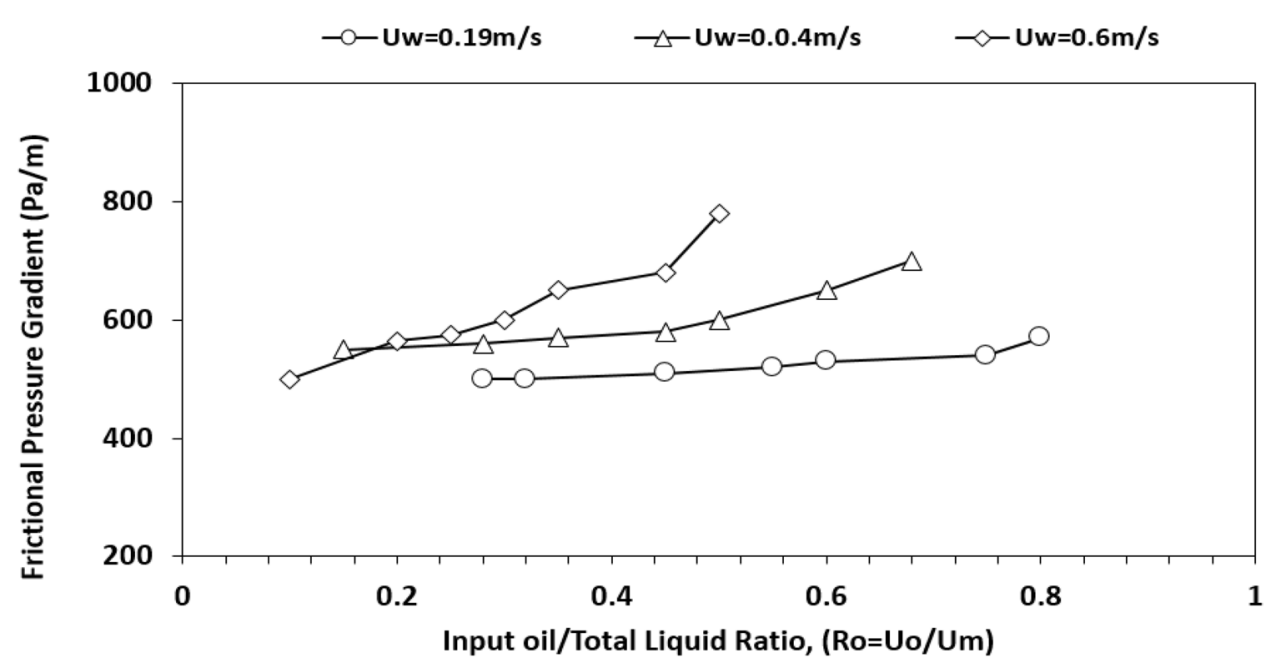


and mixture velocity, at different amount of the water holdup in the vertical pipe.

The experiments were made to measure the total pressure gradient for five fluid mixture velocities versus water holdup in vertical tubing. The results show that all the vertical flows show a similar flow pattern. Therefore, the pressure gradients increase with rising mixture fluid velocity and water cut with a similar trend. The experiment shows that for a mixture of fluid velocity below $1 \mathrm{~m} / \mathrm{s}$ the pressure gradient shows a gravity-dominated behavior with a linear rise from a pure oil to a pure water pressure gradient. This influence is because of the frictional pressure gradient which is negligible. Above mixture fluid velocity, $1 \mathrm{~m} / \mathrm{s}$ the experiments show a clear peak in the pressure gradient due to the frictional component, mainly at the point of flow patterns occurs (at a water holdup $\sim 30 \%$ ). The results concluded that the pressure gradient is highly influenced by flow patterns and flow rates. Also, oil viscosity plays a very significant role in pressure gradients, where, at identical superficial water and oil velocities, the pressure increases with the increase in oil viscosity.

The experiments showed that the total pressure gradient gradually drops with increase in the velocity of the mixture liquid if water is in a continuous phase. This happens at lower superficial water velocity. Conversely, when the oil is in a continuous phase, the total pressure gradient increases once the mixture velocity increased. Besides the illustration of the results, the pressure gradient increases with increasing $U_{\mathrm{w}}$ and $U_{\mathrm{o}}$.

In the same time, the effect of input oil/liquid ratio, $R_{\mathrm{o}}$, on the frictional pressure gradient at different superficial water velocity was investigated. The results show that the frictional pressure gradient increases as the $R_{\mathrm{o}}$ increased. Also, the frictional pressure increases once the superficial water velocity increased at the same $R_{\mathrm{o}}$. This can conclude that the frictional pressure gradient is strongly depended on the mixture velocity.

Acknowledgements The authors wish to acknowledge the LPI, Libya, for supporting this investigation project.

Open Access This article is distributed under the terms of the Creative Commons Attribution 4.0 International License (http:// creativecommons.org/licenses/by/4.0/), which permits unrestricted use, distribution, and reproduction in any medium, provided you give appropriate credit to the original author(s) and the source, provide a link to the Creative Commons license, and indicate if changes were made.

\section{References}

Barnea DA, Taitel Y (1993) A model for slug length distribution in gas-liquid flow. Int J Multiph Flow 19(5):829-838
Cook M, Behnia M (2000) Slug length prediction in near horizontal gas-liquid intermittent flow. Chem Eng Sci 55:2009-2018

Du M, Jin ND, Gao ZK, Wang ZY, Zhai LS (2012) Flow pattern and water holdup measurements of vertical upward oil-water twophase flow in small diameter pipes. Int J Multiph Flow 41:91-105

Farrar B, Bruun HH (1996) A computer based hot-film technique user for flow measurements in a vertical kerosene-water pipe flow. Int J Multiph Flow 22(4):733-751

Flores JG, Chen XT, Brill JP (1999) Characterization of oil-water flow patterns in vertical and deviated wells. SPE Prod Facil 14(2):94-101

Govier GW, Sullivan GA, Wood RK (1961) The upward vertical flow of oil-water mixtures. Can J Chem Eng 39(2):67-75

Jana AK, Das G, Das PK (2006) Flow regime identification of twophase liquid-liquid upflow through vertical pipe. Chem Eng Sci 61(5):1500-1515

Jian Z, Jing-yu X, Ying-xiang W, Dong-hui L, Hua L (2012) Experimental validation of the calculation of phase holdup for an oilwater two-phase vertical flow based on the measurement of pressure drops. J Flow Meas Instrum 31(2013):96-101

Mandhane JM, Gregory CA, Aziz K (1974) A flow pattern map for gasliquid flow in horizontal pipes. Int J Multiph Flow 1(4):537-554

McKibben MJ, Gillies RG, Shook CA (2002) A laboratory investigation of horizontal well heavy oil-water flows. Can J Chem Eng 78:743-751

Mydlarz-Gabryk K, Pietrzak M, Troniewski L (2014) Study on oil-water two-phase upflow in vertical pipes. J Pet Sci Eng 117(9):28-36

Oddie G, Shi H, Durlfosky LJ, Aziz K, Pfeffer B, Holmes JA (2003) Experimental study of two and three phase flows in large diameter inclined pipes. Int J Multiph Flow 29(4):527-558

Petalas N, Aziz K (1998) A mechanistic model for multiphase flow in pipes. J Can Pet Tech 39:43-55

Roriguez OMH, Oliemans RVA (2006) Experimental study on oilwater flow in horizontal and slightly inclined pipes. Int J of Multiph Flow 32:323-343

Russell TWF, Hodgson GW, Govier GW (1959) Horizontal pipeline flow of mixtures of oil and water. Can J Chem Eng 37:9

Taitel Y, Dukler AE (1976) A model for predicting flow regime transitions in horizontal and near horizontal gas-liquid flow. AIChE J 22:47-55

Vigneaux PG, Chenais P, Hulin JP (1988) Liquid-liquid flows in an inclined pipes. AIChE J 34(5):781-789

Xu LJ, Chen JJ, Cao Z, Zhang W, Xie RH, Liu XB, Hu JH (2016) Identification of oil-water flow patterns in a vertical well using a dual-ring conductance probe array. IEEE Trans Instrum Meas 65(5): 1249-1258

Zavareh, F., Hill, A.D., Podio, A.L., 1988. Flow regimes in vertical and inclined oil/water. SPE 18215

Zhang H-Q, Sarica C (2006) Unified modeling of gas/oil/water pipe flow-basic approaches and preliminary validation. SPE Project Facil Constr 1(2): 1-7

Zhao D, Guo L, Hu X, Zhang X, Wang X (2006) Experimental study on local characteristics of oil-water dispersed flow in a vertical pipe. Int J Multiph Flow 32:1254-1268

Publisher's Note Springer Nature remains neutral with regard to jurisdictional claims in published maps and institutional affiliations. 